\title{
Karakteristik Briket Biomassa dari Variasi Bahan Baku Dan Persentase Perekat yang Berbeda
}

\author{
Characteristics of Biomass Briquettes in term of Variations in Raw Materials and Different \\ Percentages of Adhesive
}

\author{
Agnesia Arista Wijaya AK, Ni Luh Yulianti*, Ida Bagus Putu Gunadnya. \\ Program Studi Teknik Pertanian dan Biosistem, Fakultas Teknologi Pertanian, Universitas Udayana, \\ Badung, Bali. \\ e-mail: yulianti@unud.ac.id
}

\begin{abstract}
Abstrak
Penelitian ini bertujuan untuk mengetahui karakteristik dan pengaruh jenis bahan baku dan persentase perekat yang berbeda terhadap mutu briket biomassa yang dihasilkan dan menentukan perlakuan manakah yang memberikan hasil terbaik terhadap karakteristik briket yang dihasilkan. Penelitian ini menggunakan Rancangan Acak Kelompok (RAK) Faktorial dengan menggunakan 2 faktor dan 3 kali ulangan. Faktor pertama (A) adalah jenis bahan baku yang terdiri dari 3 taraf arang bambu tabah (A1), sekam padi (A2) dan campuran bambu tabah dan sekam padi (A3). Faktor kedua (B) adalah persentase perekat yang terdiri dari 3 taraf yaitu persentase $10 \%$, (B1) $15 \%$ (B2) dan 20\%(B3). Parameter penelitian yang diamati adalah kadar air, kadar abu, kadar zat menguap dan laju pembakaran. Seluruh perlakuan diulang sebanyak 3 kali ulangan sehingga didapatkan 27 unit percobaan. Data yang diperoleh dianalisis dengan sidik ragam dan apabila terdapat pengaruh perlakuan yang signifikan, maka dilanjutkan dengan uji Duncan Multiple Test (DMRT). Berdasarakan hasil penelitian diketahui bahwa, interaksi perlakuan memberikan pengaruh yang signifikan terhadap parameter kadar air, kadar abu, kadar zat menguap dan laju pembakaran. Selanjutnya Kadar air yang didapat berkisar antar 2,30\% bb - 4,78\%bb kadar abu 5,88\% - 34,85\%, kadar zat menguap 31,30\% - 51,59\% dan laju pembakaran 73,20 gr/menit - 106,00 gr/menit. Kualitas briket yang paling baik diperoleh pada perlakuan A2B3 (arang sekam 80 gram perekat 20 gram) dimana kadar air yang dihasilkan sebesar 2,30\%bb, kadar abu 32,29\%, kadar zat menguap 32,01\% dan laju pembakarannya 92,60 gr/menit.
\end{abstract}

Kata kunci: arang bambu tabah, sekam, karakteristik briket, persentase perekat briket

\section{Abstract}

This study aims to determine the characteristics and effects of the types of raw materials and the percentage of different adhesives on the quality of the resulting briquettes and determine which treatment gives the best results for the characteristics of the resulting briquettes. This study used a factorial randomized block design (RBD) using 2 factors and 3 replications. The first factor (A) is the type of raw material which consists of 3 levels, namely tabah bamboo (A1), rice husk (A2) and a mixture of tabah bamboo and rice husk (A3). The second factor (B) is the percentage of adhesive which consists of 3 levels, namely the percentage of $10 \%$, (B1) $15 \%$ (B2) and $20 \%$ (B3). The research parameters observed were moisture content, ash content, volatile substance content and combustion rate. All treatments were repeated 3 times in order to obtain 27 experimental units. The data obtained were analyzed by means of variance and if there was a significant treatment effect, it was continued with the Duncan Multiple Test (DMRT). Based on the results of the study, it is known that the treatment interaction has a significant effect on the parameters of moisture content, ash content, volatile substance content and combustion rate. Furthermore, the water content obtained ranged from $2.30 \% \mathrm{wt}-4.78 \%$, bb ash content $5.88 \%-34.85 \%$, evaporating substance content $31.30 \%-51.59 \%$ and combustion rate $73.20 \mathrm{gr} /$ minute $-106.00 \mathrm{gr} /$ minute. The best quality of briquettes was obtained in A2B3 treatment ( 80 grams of rice husk 20 grams of adhesive) where the resulting moisture content was $2.30 \% \mathrm{BW}, 32.29 \%$ ash content, $32.01 \%$ volatile substance content and $92.60 \mathrm{gr}$ burning rate /minute.

Keywords: Tabah bamboo, husk, briquette characteristics, adhesive percentage briquettes.

\section{PENDAHULUAN}

Bidang energi mempunyai posisi penting dalam hal membantu kelangsungan proses pembangunan nasional (Iskandar \& Rofiatin, 2017) dengan berkembangnya jumlah masyarakat yang terus bertambah mengakibatkan permintaan energi bertambah besar. Selain itu penggunaan bahan bakar fosil menyebabkan kerusakan lingkungan, tidak dapat diperbaharui dan tidak berkelanjutan (Hastiawan et al., 2018). Hal ini menyebabkan terjadinya kekurangan bahan bakar di massa yang depan. Oleh karena itu, maka wajib diusahakan sumber alternatif pengganti yang bersumber dari 
bahan baku bersifat berlanjut dan dapat diperbaharui seperti energi biomassa. Biomassa merupakan salah satu energi pengganti yang berpotensi terdapat banyak di Indonesia bahkan banyak sekali dijumpai dilingkungan sekitar. Dari lain pihak, Indonesia sebagai negara agraris banyak mempunyai limbah pertanian yang tidak terpakai serta merupakan sumber energi alternatif melimpah memiliki kandungan energi yang relatif tinggi. Limbah pertanian tersebut dapat dibuat menjadi suatu bahan bakar padat buatan sebagai bahan bakar alternatif yang disebut briket (Ningsih et al., 2016).

Mutu briket yang baik ialah briket yang mempunyai standar mutu agar bisa digunakan sesuai kebutuhannya. Mutu briket rata-rata ditentukan dari sifat fisik dan kimia seperti kadar air, kadar abu, nilai kalor dan bagian yang hilang pada suhu $950^{\circ} \mathrm{C}$ (Hendra, 2007). Selanjutnya untuk dapat menghasilkan briket dengan kualitas yang baik dan memenuhi standar mutu, maka bahan baku yang digunakan juga harus memenuhi standar untuk pembuatan briket. Terdapat banyak sekali biomassa yang dapat menjadi bahan baku pembuatan briket beberapa diantaranya adalah bambu tabah dan sekam padi (Vachlepi \& Suwardin, 2013).

Bambu yaitu salah satu jenis tumbuhan yang dapat menjadi bahan baku sumber alternatif yang bersifat kontinyu dan dapat terus diperbaharui disamping itu bambu juga mempunyai kandungan lignin yang cukup tinggi. Diantaranya jenis bambu yang yang memiliki sifat dengan kandungan lignin yang tinggi adalah bambu tabah yaitu sebesar $22,19 \%$ dan selulosa sebesar 44,94\% sehingga baik untuk dijadikan bahan baku pembuatan briket (Kencana et al., 2012). Menurut penelitian tentang briket yang sudah dilakukan oleh Musabbikhah et al., (2015) menngatakan bahwa pembuatan briket dari campuran beberapa jenis bahan baku biomassa menghasilkan beberapa kelebihan diantaranya tingginya kandungan karbon briket yang dihasilkan. Selama ini penggunaan bambu khususnya bambu tabah, sekam padi dan campuran antara bambu tabah dengan biomasa lainnya seperti sekam belum dilakukan.

Selain jenis bahan baku, jenis perekat dan persentase perekat pada pembuatan briket juga memiliki pengaruh yang cukup signifikan terhadap kualitas briket yang diperoleh. Berdasarkan penelitian yang telah dilakukan oleh Silviana \& Purbasari, 2009 mengenai pembuatan briket dengan bahan baku limbah kulit nyamplung menggunakan 3 jenis perekat yaitu natrium silikat, tepung terigu dan tepung tapioka menghasilkan bahwa jenis perekat yang terbaik yaitu tepung tapioka karena memiliki karbon sebesar $84,7 \%$, sehingga mampu menghasilkan kualitas briket yang lebih baik dibandingkan perlakuan lainnya.

Berdasarkan beberapa penjelasan diatas, maka perlu adanya penelitian untuk mengetahui karakteristik briket biomassa dari variasi bahan baku dan persentase perekat yang berbeda dan selanjutnya menentukan perlakuan manakah yang memberikan hasil terbaik terhadap karakteristik briket yang dihasilkan.

\section{METODE PENELITIAN}

\section{Tempat dan Waktu Penelitian}

Penelitian ini dilakukan di Lab Pascapanen dan Lab Rekayasa Proses dan Pengendalian Mutu Gedung Agrokomplek Universitas Udayana. Waktu penelitian dari bulan Juli 2020 - Agustus 2020.

\section{Alat dan Bahan}

Alat yang digunakan dalam penelitian ini terdiri dari, furnace (Merk Barnstead/Thermolyne type 47900), wadah plastik, oven (Labo DO 255), cetakan briket besi balok, timbangan analitik (AND GF 300), cawan aluminium, cawan porselin, kompor listrik (Maspion S-301), kompor gas portable (Kris Chef) alat kempa (Alat Press ban), blender (Merk Panasonic) alat tumbuk kayu, desikator, ayakan (ayakan 40 mesh farmasi).

Bahan yang digunakan adalah bambu tabah sekitar umur 4 tahun dari Desa Pupuan Tabanan, sekam padi dari Penggilingan beras Desa Buduk Badung, tepung kanji Rose Brand dan air.

\section{Rancangan Percobaan}

Penelitian ini dirancang menggunakan Rancangan Acak Kelompok (RAK) Faktorial yang terdiri dari dua faktor perlakuan dan masing-masing faktor terdiri dari tiga taraf:

- Faktor pertama adalah jenis bahan baku:

- A1. Arang bambu tabah (100\%)

- A2. Arang sekam padi $(100 \%)$

- A3. Arang bambu tabah dan sekam padi (50\%: 50\%)

- Faktor kedua adalah persentase bahan perekat berupa kanji perbandingan 10\%, 15\%, 20\% dari $100 \mathrm{gr}$ campuran yang digunakan:

○ B1. Tepung kanji $10 \%=10$ gram

○ B2. Tepung kanji $15 \%=15$ gram

○ B3. Tepung kanji $20 \%=20$ gram

O

Kombinasi rancangan percobaan penelitian yang akan diperoleh adalah sebagai berikut: 
1. $\mathrm{A} 1 \mathrm{~B} 1=$ bahan baku arang bambu tabah dengan perekat sebanyak 10\% (menggunakan arang bambu tabah $100 \%$ sebanyak 90 gram dan perekat tepung kanji sebanyak 10 gram).

2. $\mathrm{A} 1 \mathrm{~B} 2$ = bahan baku arang bambu tabah dengan perekat sebanyak 15\% (menggunakan arang bambu tabah $100 \%$ sebanyak 85 gram dan perekat tepung kanji sebanyak 15 gram).

3. A1B3 = bahan baku arang bambu tabah dengan perekat sebanyak 20\% (menggunakan arang bambu tabah $100 \%$ sebanyak 80 gram dan perekat tepung kanji sebanyak 20 gram).

4. $\mathrm{A} 2 \mathrm{~B} 1$ = bahan baku arang sekam padi dengan perekat sebanyak $10 \%$ (menggunakan arang sekam padi $100 \%$ sebanyak 90 gram dan perekat tepung kanji sebanyak 90 gram).

5. $\mathrm{A} 2 \mathrm{~B} 2$ = bahan baku arang sekam padi dengan perekat sebanyak 15\% (menggunakan arang sekam padi $100 \%$ sebanyak 85 gram dan perekat tepung kanji sebanyak 10 gram).

6. $\mathrm{A} 2 \mathrm{~B} 3$ = bahan baku arang sekam padi dengan perekat sebanyak 20\% (menggunakan arang sekam padi $100 \%$ sebanyak 80 gram dan perekat tepung kanji sebanyak 20 gram).

7. $\mathrm{A} 3 \mathrm{~B} 1=$ bahan baku arang bambu tabah dan arang sekam padi dengan perekat sebanyak $10 \%$ (menggunakan arang bambu tabah 50\% dan arang sekam padi $50 \%$ sebanyak 45 gram arang arang bambu tabah dan arang sekam padi 45 gram serta perekat tepung kanji 10 gram).

8. $\mathrm{A} 3 \mathrm{~B} 2$ = bahan baku arang bambu tabah dan arang sekam padi dengan perekat sebanyak $15 \%$ (menggunakan arang bambu tabah 50\% dan arang sekam padi $50 \%$ sebanyak 42,5 gram arang bambu tabah dan arang sekam padi sebanyak 42,5 gram serta perekat tepung kanji sebanyak 15 gram).

9. $\mathrm{A} 3 \mathrm{~B} 3$ = bahan baku arang bambu tabah dan arang sekam padi dengan perekat sebanyak $20 \%$ (menggunakan arang bambu tabah 50\% dan arang sekam padi $50 \%$ sebanyak 40 gram arang bambu tabah dan arang sekam padi sebanyak 40 gram serta perekat tepung kanji sebanyak 20 gram).

\section{Tahapan Penelitian}

\section{Persiapan bahan baku arang briket}

Untuk tahapan pertama ini persiapkan bambu tabah dan sekam padi. Bambu yang digunakan berumur sekitar 4 tahun memiliki diameter $3 \mathrm{~cm}$ dengan tebal bambu rata - rata adalah sebesar $1 \mathrm{~cm}$. Selanjutnya, bambu dipotong menggunakan gergaji sepanjang $5 \mathrm{~cm}$ dan dibersihkan. Sekam padi yang digunakan adalah sekam padi limbah dari proses hasil penggilingan beras yang dalam keadaan kering, selanjutnya dilakukan proses pengarangan pada bahan baku tersebut.

\section{Proses pengarangan/pirolisis}

Bambu tabah dan sekam padi selanjutnya dimasukan ke dalam alat furnace dengan suhu $300^{\circ} \mathrm{C}$ selama $1 \mathrm{jam}$. Dalam proses pengarangan sekam padi dan bambu ditaruh dalam wadah cawan porselin besar lalu bahan baku dimasukan kedalam alat furnace sehingga bahan baku menjadi berwarna hitam dan siap menjadi arang.

\section{Penghancuran dan pengayakan}

Arang bambu tabah dan arang sekam padi dihancurkan dengan cara ditumbuk dan diblender, setelah selesai diblender maka diayak dengan menggunakan ayakan 40 mesh, ayakan yang digunakan adalah ayakan dengan menggunakan goyangan tangan. Hal ini dilakukan dengan tujuan untuk menghasilkan butiran yang lebih halus, lebih seragam dan layak dijadikan briket.

\section{Pembuatan perekat.}

Perekat berbahan baku tepung kanji dibuat dengan perbandingan bahan baku 1:1 kemudian air dipanaskan hingga mendidih, lalu tepung tapioka dimasukan dalam panci yang sudah berisi air mendidih, aduk tepung dan air sehingga berubah menjadi lem dan siap digunakan.

\section{Pencampuran arang dengan perekat.}

Perekat kanji dan bahan baku ditimbang sesuai perlakuan. Masing-masing unit perlakuan memiliki berat total sebanyak 100 gram. Sebagai contoh untuk perlakuan A1B1 (bambu 90 gram perekat 10 gram). Wadah plastik diisi dengan serbuk arang lalu diberi perekat dan bahan dicampurkan menggunakan tangan sehingga bahan dan perekat menjadi satu.

\section{Pencetakan}

Setelah bahan dicampurkan maka dilakukan pencetakan briket menggunakan cetakan berbentuk balok berukuran $3 \times 2 \times 3 \mathrm{~cm}$ lalu dikempa dengan alat kempa selama 3 menit sampai kondisi briket arang berubah menjadi berbentuk balok dan padat.

\section{Pengeringan}

Briket arang yang dihasilkan kemudian dikeringkan menggunakan oven dengan suhu $105^{\circ} \mathrm{C}$ dengan waktu 4 jam, setelah selesai dioven briket diangin-anginkan selama 24 jam, lalu dikemas menggunakan toples agar briket selalu kering dan tidak basah. 


\section{Parameter yang diamati}

\section{Kadar air}

Cara pengujian kadar air sebagai berikut:

Cawan yang telah dibersihkan dikeringkan dalam oven menggunakan suhu $105^{\circ} \mathrm{C}$ selama 1 jam, lalu diamkan dalam desikator selama 15 menit lalu ditimbang. Timbang masing-masing massa cawan dan sampel sebanyak 3 gram, kemudian sampel dikeringkan dengan menggunakan oven dengan suhu $105^{\circ} \mathrm{C}$ selama 24 jam. Sampel dimasukan kedalam desikator selama 15 menit setelah itu ditimbang, lalu penimbangan dan pengeringan secara berulang dengan 27 sampel. Hitunglah kadar air (\%) dengan persamaan:

$$
\text { Kadar air }(\%)=\frac{W o-W}{W s o} x 100 \%
$$

Dimana,

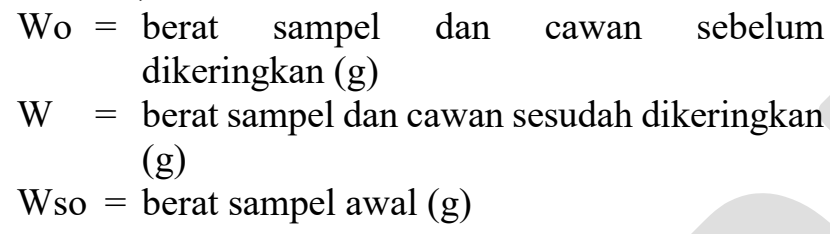

\section{kadar abu}

Cara pengujian kadar abu yakni:

Cawan porselin yang telah dibersihkan dimasukan ke dalam oven selama 1 jam pada suhu $105^{\circ} \mathrm{C}$, lalu timbang 3 gram sampel ke dalam cawan porselin. Bakar menggunakan kompor listrik sebelum dimasukan ke furnace sehingga asapnya hilang, lalu masukkan sample ke dalam furnace pada suhu $600-800^{\circ} \mathrm{C}$ selama 3 jam sehingga menjadi abu. dinginkan cawan beserta isinya ke dalam desikator selama 15 menit kemudian ditimbang untuk mendapatkan berat abu. Hitunglah kadar abu (\%) dengan persamaan:

Dimana,

$$
\text { Kadar abu }(\%)=\frac{W o}{W d s o} \times 100 \%
$$

Wo $=$ berat sampel setelah pengabuan $(\mathrm{g})$

$\mathrm{Wdso}=$ berat sampel sebelum pengabuan $(\mathrm{g})$

\section{Volatille matter}

Cara pengujian volatille matter adalah

Cawan porselin ditimbang terlebih dahulu massanya, lalu masukkan dalam cawan porselin dan diberi dengan sampel sebanyak 3 gram, kemudian ditimbang. Panaskan ke dalam furnace menggunakan suhu $750^{\circ} \mathrm{C}$ selama 7 menit, setelah itu dinginkan dalam desikator selama $1 / 2$ jam kemudian ditimbang Hitunglah kadar zat menguap (\%) dengan persamaan:

$$
\text { Kadar volatille }(\%)=\frac{W o-W}{W o} x 100 \%
$$

\author{
Dimana, \\ $\mathrm{Wo}=$ kadar sampel awal (g) \\ $\mathrm{W}=$ berat sampel akhir
}

\section{Laju Pembakaran}

Pengujian laju pembakaran ini untuk memperoleh kecepatan briket dari terbakar sehingga menjadi abu. Menurut Sudding \& Jamaluddin, 2015 adalah karakteristik pembakaran pada briket, yang telah dilakukan sebagai tolak ukur untuk mendapatkan bahan bakar yang efisien dalam penggunaannya. Disediakan sampel lalu ditimbang bobot briket sebelum melakukan pengujian laju pembakaran. Selanjutnya, disiapkan kayu yang sudah di nyalakan apinya lalu briket diletakkan diatas kawat kasa. Setelah briket sudah terbakar, kayu yang sudah menyala segera dipindahkan dan lama nyalanya briket dihitung menggunakan stopwatch hingga briket padam. Persamaan yang digunakan untuk mengetahui laju pembakaran adalah (Batubara \& Jamilatun, 2012) :

$$
\text { Laju pembakaran }(\mathrm{LP})=\frac{m}{t}
$$

Keterangan:

$$
\begin{aligned}
\mathrm{Lp} & =\text { Laju pembakaran (gr/menit) } \\
\mathrm{m} & =\text { Bobot sampel }(\mathrm{gr}) \\
\mathrm{t} & =\text { Waktu pembakaran (menit) }
\end{aligned}
$$

\section{Analisis Data}

Data yang diperoleh akan dianalisis menggunakan sidik ragam apabila pengaruh perlakuan signifikan, maka dilanjutkan dengan mengetahui perbedaan antar rerata perlakuan dilakukan analisis varian yang ditunjukan dengan uji Duncan Multiple Test (DMRT).

\section{HASIL DAN PEMBAHASAN}

\section{Kadar air}

Kadar air merupakan salah satu parameter yang sangat penting bagi proses pengeringan salah satunya adalah menentukan karakteristik briket yang baik, dimana kadar air yang rendah sangat berpengaruh nyata terhadap briket. Hasil analisis keragaman memperlihatkan bahwa interaksi perlakuan antar bahan baku (faktor A) dan perlakuan persentase perekat (faktor B) memberikan pengaruh yang signifikan terhadap parameter kadar air briket yang dihasilkan. Pengaruh interaksi perlakuan bahan baku dan perekat terhadap kadar air briket bioarang dapat dilihat pada gambar 1 dan tabel 1 . 


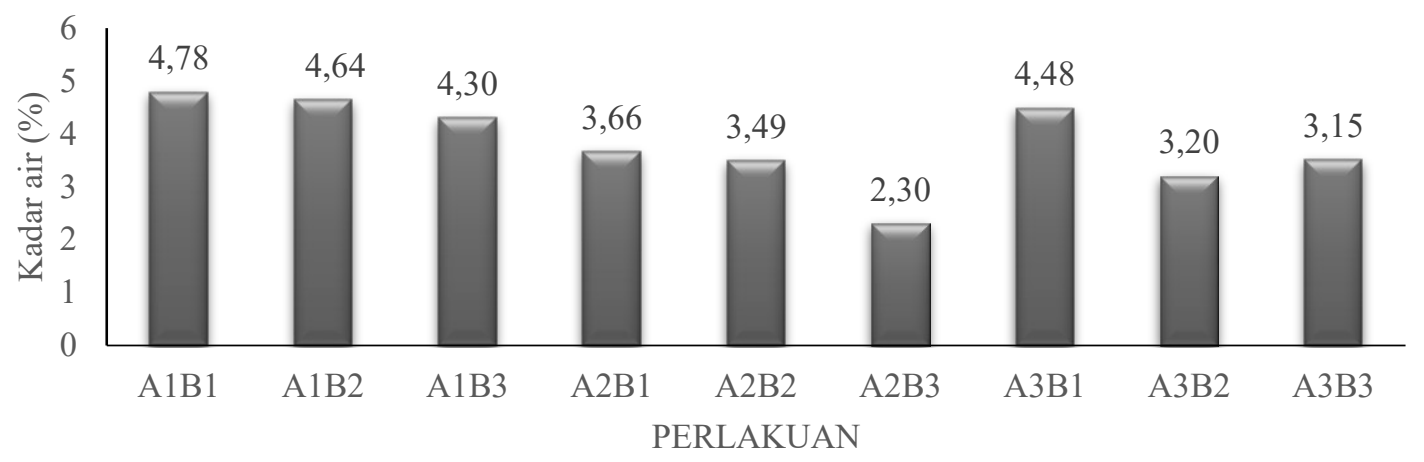

Gambar 1. Grafik interaksi perlakuan bahan baku dan perekat terhadap kadar air briket.

Tabel 1. Nilai kadar air (\% bb) berdasarkan perlakuan jenis bahan baku dan persentase perekat.

\begin{tabular}{|c|c|c|c|}
\hline \multirow[b]{2}{*}{ BAHAN BAKU } & \multicolumn{3}{|c|}{ PERSENTASE PEREKAT } \\
\hline & $\begin{array}{l}10 \% \\
(\mathrm{~B} 1)\end{array}$ & $\begin{array}{l}15 \% \\
(\mathrm{~B} 2)\end{array}$ & $\begin{array}{l}20 \% \\
(\mathrm{~B} 3)\end{array}$ \\
\hline $\begin{array}{l}\text { Arang bambu tabah } \\
\text { (A1) }\end{array}$ & $4,78 c$ & $4,64 c$ & $4,30 c$ \\
\hline $\begin{array}{l}\text { Arang Sekam padi } \\
\text { (A2) }\end{array}$ & $3,66 b$ & $3,49 b$ & $2,30 a$ \\
\hline $\begin{array}{l}\text { Arang bambu tabah } \\
\text { dan sekam padi } \\
\text { (A3) }\end{array}$ & $4,48 c$ & $3,20 b$ & $3,15 b$ \\
\hline
\end{tabular}

Selanjutnya, pada gambar 1 dan tabel 1 diketahui bahwa kadar air briket yang diperoleh berada pada kisaran $2,30 \% \mathrm{bb}-4,78 \% \mathrm{bb}$, dan nilai ini sudah memenuhi standar nilai SNI yang diacu, dimana berdasarkan nilai SNI kadar air yang baik untuk produk briket adalah dibawah $8 \%$ bb. Selanjutnya dari data-data yang dihasilkan pada tabel 1 tersebut juga dapat dilihat bahwa perlakuan A2B3 (arang sekam padi 80 gram dan perekat 20 gram) memiliki kadar air paling rendah yaitu sebesar $2,30 \%$ bb dan perlakuan ini memberikan pengaruh yang berbeda nyata dibandingkan perlakuan lainnya.

Rendahnya nilai kadar air yang diperoleh pada perlakuan A2B3 kemungkinan disebabkan karena sekam padi memiliki porositas yang cukup tinggi yaitu sebesar $79 \%$, hal ini menyebabkan rongga dalam briket lebih besar dan memudahkan air yang berada didalam bahan untuk menguap keluar lingkungan selama proses pengeringan. Akibatnya jumlah air yang mampu dikeluarkan dari dalam bahan menjadi lebih banyak dan menyebabkan kadar air mampu dicapai menjadi lebih rendah. Menurut penelitian yang dilakukan Faiz et al., 2015 yang mengungkapkan bahwa semakin tinggi kerapatan maka rongga-rongga antar partikel arang akan bertambah rapat karena padunya partikel-partikel tersebut sehingga tidak adanya celah atau ruang hampa. Menurut Wibowo, 2009 menyatakan bahwa bahan perekat yang baik dipakai untuk membuat briket adalah pati, dekstrin, dan tepung kanji, karena menghasilkan briket arang yang tidak berasap pada saat pembakaran dan tahan lama.

Selanjutnya dari data pada gambar 4 juga dapat diketahui bahwa kadar air tertinggi diperoleh dari perlakuan A1B1 (arang bambu tabah 90 gram dan perekat 10 gram) hal ini disebabkan oleh bambu merupakan tumbuhan dari golongan rumputrumputan mempunyai kelebihan daya hisap daunnya lebih kuat agar bisa hidup sehingga kadar airnya menjadi banyak. Siwi et al., 2017 menyatakan bahwa jumlah pori-pori yang lebih banyak dan terdapat kandungan komponen- komponen kimia, diantaranya selulosa, lignin juga bisa mempengaruhi adanya nilai kadar air pada briket. Kadar air yang dihasilkan menunjukan adanya kecenderungan komposisi bahan baku dan penambahan persentase perekat. Hal ini dikarenakan terdapat penambahan kadar air dari bahan perekat dan bahan baku itu sendiri sehingga kadar air briket akan meningkat juga (Isa, 2012).

Selain berpengaruh pada susah tidaknya briket terbakar, kadar air juga akan mempengaruhi nilai kalor yang dimiliki oleh briket. Semakin rendah kadar air briket maka semakin tinggi nilai kalor yang diperoleh pada briket. Hal ini diakibatkan karena dengan kecilnya kadar air, maka kalor yang dihasilkan untuk menguapkan air juga sedikit, sehingga energi kalor yang tertinggal pada briket akan semakin tinggi (Putra \& Indonesia, 2018)

\section{Kadar abu}

Kadar abu merupakan parameter yang penting kedua selain kadar air bagi proses pengeringan karena kadar abu menentukan karakteristik briket yang baik, dimana kadar abu yang rendah sangat mempengaruhi kualitas briket yang dihasilkan. Hasil analisis keragaman memperlihatkan bahwa interaksi 
perlakuan bahan baku (faktor A) dan perekat (faktor B) berpengaruh yang signifikan terhadap parameter kadar abu. Pengaruh interaksi perlakuan bahan baku dan perekat terhadap kadar abu briket bioarang dapat dilihat pada Gambar 2 dan Tabel 2

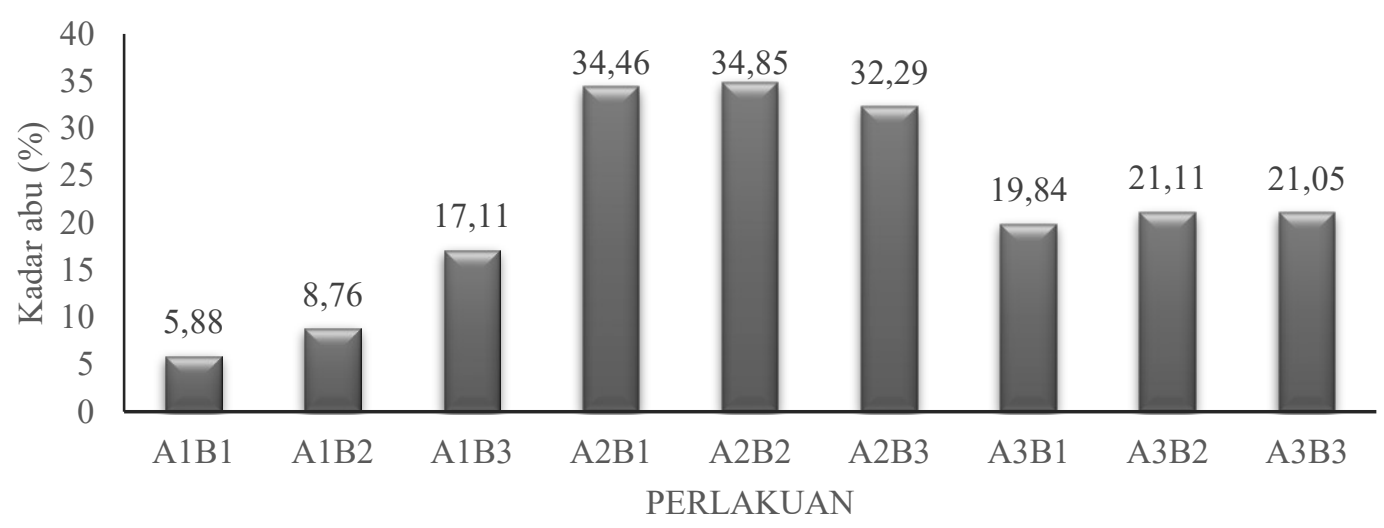

Gambar 2. Grafik interaksi perlakuan bahan baku dan perekat terhadap kadar abu briket.

Tabel 2. Nilai kadar abu (\%) berdasarkan perlakuan jenis bahan baku dan persentase perekat.

\begin{tabular}{lccc}
\hline & \multicolumn{3}{c}{ PERSENTASE PEREKAT } \\
BAHAN BAKU & $10 \%$ & $15 \%$ & $20 \%$ \\
& (B1) & (B2) & (B3) \\
\hline $\begin{array}{l}\text { Arang bambu tabah } \\
\text { (A1) }\end{array}$ & $5,88 a$ & $8,76 a$ & $17,11 b$ \\
$\begin{array}{l}\text { Arang Sekam padi } \\
\text { (A2) }\end{array}$ & $34,46 c$ & $34,85 c$ & $32,29 c$ \\
$\begin{array}{l}\text { Arang bambu tabah } \\
\text { dan sekam padi }\end{array}$ & $19,84 b$ & $21,11 b$ & $21,05 b$ \\
\hline
\end{tabular}
(A3)

Keterangan: Huruf yang beda dibelakang nilai ratarata menunjukan nilai berbeda nyata $(P>0,05)$.

Selanjutnya, berdasarkan data pada gambar 2 dan tabel 2 diketahui bahwa kadar abu briket yang dihasilkan berada kisaran 5,88\% - 34,85\%, dari nilai tersebut ada yang sudah memenuhi standar SNI dan belum memenuhi standar nilai SNI yang diacu, dimana berdasarkan nilai SNI kadar abu yang baik adalah dibawah $8 \%$. Selanjutnya dari data-data tersebut juga dapat dilihat bahwa perlakuan A1B1 (arang bambu tabah 90gram dan perekat 10\%) memiliki kadar abu paling rendah yaitu sebesar $5,88 \%$ dan perlakuan ini memberikan pengaruh yang tidak berbeda nyata dengan A1B2, namun berbeda nyata dengan perlakuan lainnya.

Rendahnya nilai kadar abu yang dihasilkan pada perlakuan A1B1, kemungkinan disebabkan adanya kandungan silika yang terdapat pada bambu lebih rendah dibandingkan kandungan silika pada bahan baku sekam padi, selanjutnya kandungan silika tersebut merupakan salah satu unsur utama pembentuk abu selain bahan kimia pembentuk lainnya. Semakin rendah nilai kadar abu, semakin bagus kualitas briket. Abu adalah bagian tertinggal dari proses pembakaran yang sudah tidak mempunyai unsur karbon lagi. Bagian utama abu yaitu silika serta berpengaruh kurang baik terhadap nilai kalor yang didapat. Semakin tinggi kadar abu maka semakin rendah kualitas briket karena kandungan abu semakin tinggi dapat menurunkan nilai kalor (Muhammad et al., 2018). Kandungan silika yang terdapat pada sekam padi mencapai 93.2 $\%$ sementara bahan lainnya seperti bambu berada dibawahnya dengan kandungan silika hanya sebesar 75.90\% (Sa'diyah et al., 2016).

Selanjutnya dari data pada gambar 2 juga dapat diketahui bahwa kadar abu tertinggi diperoleh dari perlakuan A2B2 (arang sekam 85 gram dan perekat 15 gram) kemungkinan hal ini dikarenakan selain karena kandungan silika yang tinggi pada pada bahan baku sekam padi juga dikarenakan persentase perekat yang cukup tinggi pada perlakuan tersebut. Sehingga menambah persentase abu yang dihasilkan. Menurut Wibowo, 2009, kadar abu yang tinggi bisa menurunkan nilai kalor briket arang membuat mutu briket arang tersebut menurun. Wibowo, 2009 mengatakan bahwa kadar abu mampu berpengaruh terhadap kadar karbon terikat. Penambahan kosentrasi arang akan menyebabkan naiknya nilai kadar abu briket dan penurunan kosentrasi arang akan menurunkan nilai kadar abu briket. .(Siwi et al., 2017).

\section{Kadar zat menguap (Volatille matter)}

Kadar zat menguap (Volatille matter) merupakan parameter yang menentukan bagus tidaknya karakteristik briket yang terbakar, jika kadar zat menguap itu rendah maka briket akan mudah terbakar dan jika kadar zat menguap briket tinggi maka sulit akan terbakar. Kandungan 
volatille matter yang terdapat adalah $\mathrm{CO}, \mathrm{CO}_{2}, \mathrm{CH}_{4}$ dan $\mathrm{H}_{2}$. (Sudarja, 2009).

Hasil analisis keragaman memperlihatkan bahwa interaksi perlakuan bahan baku (faktor A) dan perekat (faktor B) berpengaruh yang signifikan terhadap parameter kadar zat menguap. Pengaruh interaksi perlakuan bahan baku dan perekat terhadap kadar zat menguap briket bioarang dapat dilihat pada gambar 3 dan tabel 3 .

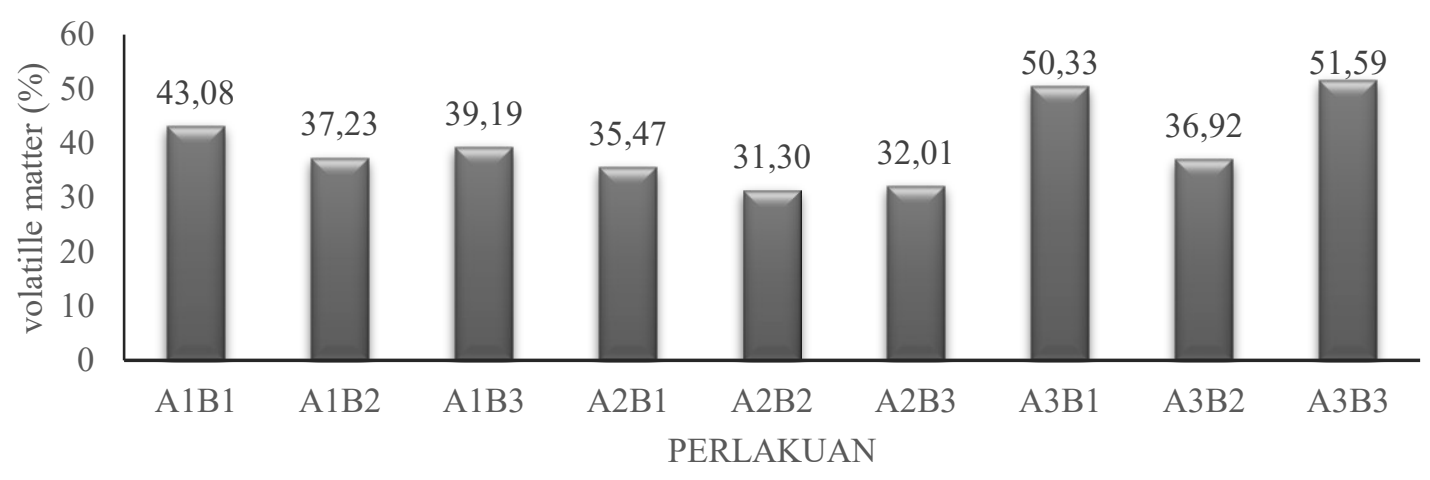

Gambar 3. Grafik interaksi perlakuan bahan baku dan perekat terhadap kadar zat menguap briket. rendahnya nilai volatille matter pada perlakuan tersebut. perekat pati dalam berbentuk cair sebagai

Tabel 3. Volatille matter (\%) berdasarkan perlakuan jenis bahan baku dan persentase perekat. PERSENTASE PEREKAT

\begin{tabular}{|c|c|c|c|}
\hline \multirow[b]{2}{*}{ BAHAN BAKU } & \multicolumn{3}{|l|}{. } \\
\hline & $\begin{array}{l}10 \% \\
(\mathrm{~B} 1)\end{array}$ & $\begin{array}{l}15 \% \\
(\mathrm{~B} 2)\end{array}$ & $\begin{array}{l}20 \% \\
\text { (B3) }\end{array}$ \\
\hline $\begin{array}{l}\text { Arang bambu } \\
\text { tabah (A1) }\end{array}$ & $43,08 d$ & $37,23 b c$ & $39,19 c d$ \\
\hline $\begin{array}{l}\text { Arang Sekam } \\
\text { padi (A2) }\end{array}$ & $35,47 a b c$ & $31,30 a$ & $32,01 a b$ \\
\hline $\begin{array}{l}\text { Arang bambu } \\
\text { tabah dan sekam } \\
\text { padi (A3) }\end{array}$ & $50,33 e$ & $36,92 b c$ & $51,59 e$ \\
\hline
\end{tabular}

Selanjutnya, pada Gambar 3 dan Tabel 3 diketahui bahwa kadar zat menguap briket yang dihasilkan berada kisaran $31,30 \%$ - 51,59\%, semakin rendah kandungan zat menguap yang terdapat pada bahan maka kualitas briket tersebut akan bertambah baik. Selanjutnya dari data-data tersebut juga dapat dilihat bahwa perlakuan A2B2 (arang sekam padi 85 gram dan perekat 15 gram) memiliki kadar zat menguap paling rendah yaitu sebesar $31,30 \%$ dan perlakuan ini memberikan pengaruh yang tidak berbeda nyata dengan A2B1 dan A2B3, namun berbeda nyata dengan perlakuan lainnya. Dalam standar SNI kadar zat menguap harus berada dibawah $15 \%$.

Rendahnya nilai kadar zat menguap pada perlakuan A2B2 (arang sekam 85gram perekat 15 gram). kemungkinan disebabkan oleh penggunaan pati sebagai bahan perekat dan dengan persentase yang cukup tinggi menjadi salah satu penyebab bahan perekat menghasilkan briket dengan kadar zat menguap yang bernilai rendah (Sudding \& Jamaluddin, 2015).

Selanjutnya dari data 3 diketahui bahwa perlakuan A3B3 (campuran arang bambu tabah 40 gram arang sekam padi 40 gram dan perekat 20 gram) memiliki kadar zat menguap yang tertinggi kemungkinan diakibatkan jenis campuran bahan baku yang berbeda jenis dan kandungan silika pada 2 jenis bahan baku ini sangat tinggi yang menyebabkan kadar zat menguapnya sangat tinggi. Menurut Hendra, 2007 besar kecilnya senyawa volatille yang diperoleh dipengaruhi oleh jenis jenis bahan baku, sebab perbedaan variasi bahan baku berpengaruh nyala nilai senyawa volatille tiap briket arang. Menurut Ismayana \& Afriyanto, 2011, bahwa perekat kanji dalam penggunaanya pada pembuatan briket menimbulkan asap yang relative sedikit.

Besarnya kadar volatille matter dipengaruhi oleh penambahan perekat. Karena perekat yang digunakan tidak mengalami proses pirolisis. Semakin rendah kadar volatille matter maka briket akan menghasilkan asap yang lebih sedikit saat digunakan (Putra \& Indonesia, 2018)

\section{Laju pembakaran}

Laju pembakaran merupakan parameter yang menentukan karakteristik briket terhadap lama atau tidaknya waktu dalam pembakaran yang terjadi, jika waktu laju pembakarannya lama maka briket bisa dikatakan baik. Hasil analisis keragaman memperlihatkan bahwa interaksi perlakuan bahan baku (faktor A) dan perekat (faktor B) berpengaruh 
yang signifikan terhadap parameter laju pembakaran. Pengaruh interaksi perlakuan bahan baku dan perekat terhadap kadar zat menguap briket bioarang dapat dilihat pada gambar 4 dan tabel 4 .

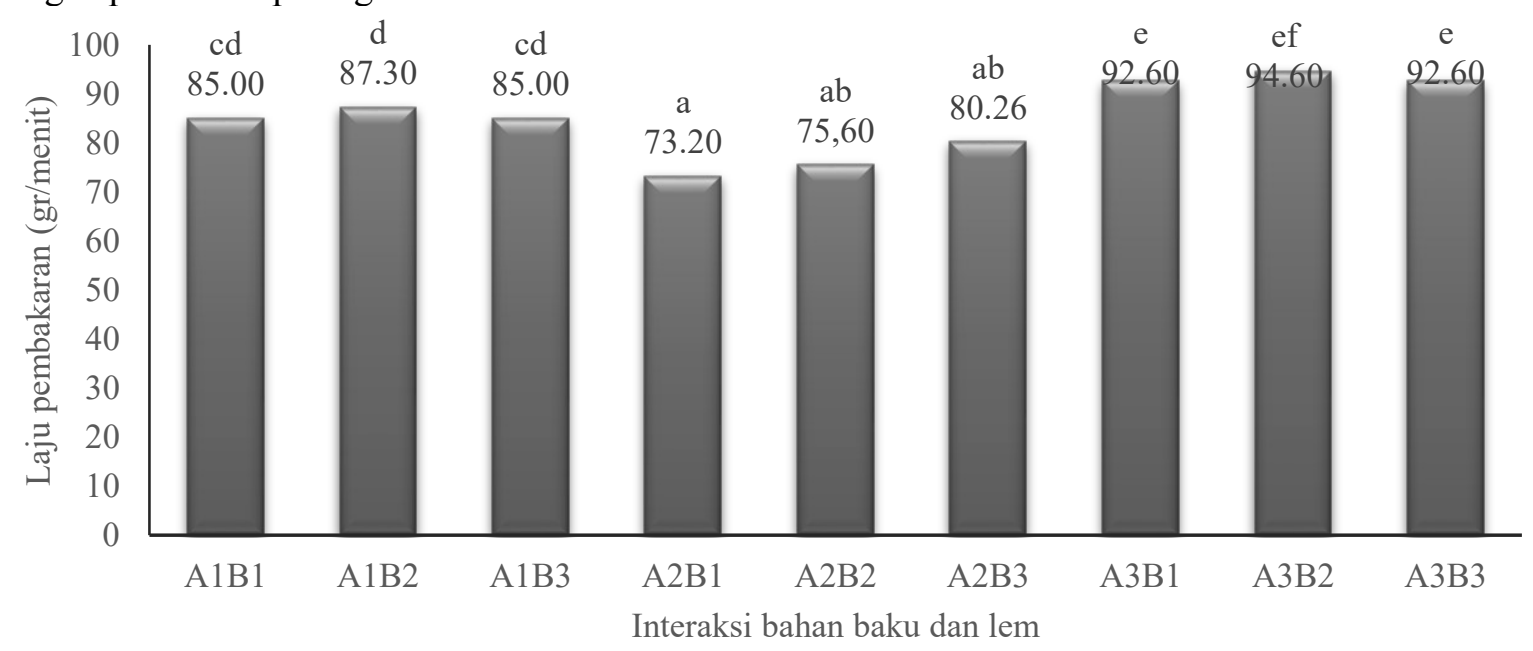

Gambar 4. Grafik interaksi perlakuan bahan baku dan perekat terhadap laju pembakaran briket.

Tabel 4. Laju pembakaran (gr/mnt) berdasarkan perlakuan jenis bahan baku dan persentase perekat.

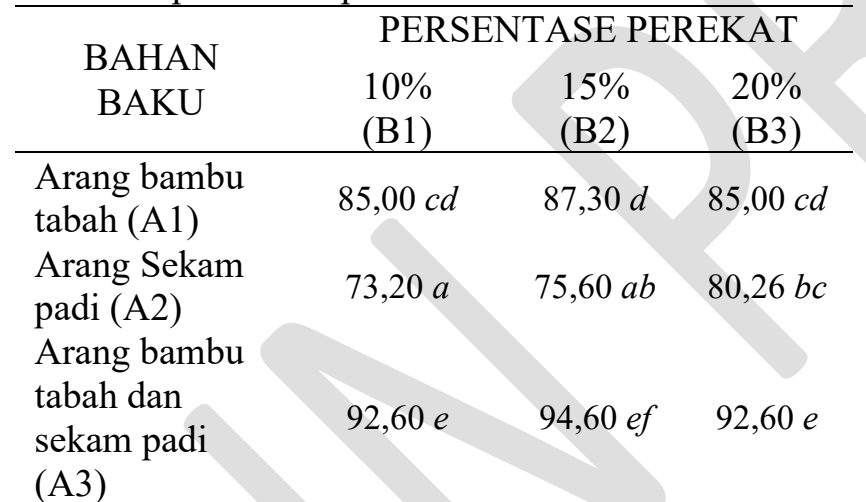

Keterangan: Huruf yang beda dibelakang nilai rata-rata menunjukan nilai berbeda nyata $(\mathrm{P}>0,05)$.

Selanjutnya, pada gambar 4 dan tabel 4 diketahui bahwa laju pembakaran briket yang dihasilkan berada kisaran 73,20 gr/mnt - 94,60 gr/mnt, dan nilai ini tidak ada dalam SNI, namun jika briket memiliki waktu yang terendah maka karakteristik briket bisa dikatakan baik, karena memiliki kadar abu yang sedikit, tingginya transfer panas ke dalam briket dan memiliki kadar karbon yang rendah sehingga tidak mempunyai banyak emisi debu dalam pembakarannya. Selanjutnya dari data-data tersebut juga dapat dilihat bahwa perlakuan A2B1 (arang sekam padi 90 gram dan perekat 10 gram) memiliki laju pembakaran paling terendah yaitu sebesar 73,20 gr/mnt dan perlakuan ini memberikan pengaruh yang tidak berbeda nyata dengan perlakuan A2B2 (arang sekam padi 85 gram

dan perekat 15 gram), namun memperoleh pengaruh yang berbeda nyata dibandingkan perlakuan lainnya. Rendahnya nilai laju pembakaran pada perlakuan ini, kemungkinan disebabkan oleh karbon yang terkandung dalam sekam tinggi dan ukuran partikel serbuk sekam lebih kecil dibandingkan bahan baku lainnya. Menurut (Yorganc1, 2018) menyatakan jika laju pembakaran arang tergantung pada persentase oksigen, temperatur gas, bilangan Reynold, ukuran dan porositas arang. Penggunaan jenis dan persentase perekat pada pembuatan briket adalah salah satu faktor penting dalam pembuatan briket (Handayani \& Suryaningsih, 2019).

Selanjutnya dari data 4 menunjukan bahwa laju pembakaran yang tertinggi dimiliki oleh A3B2. tingginya nilai laju pembakaran yang diperoleh pada perlakuan, itu menyebabkan jumlah briket yang terbakar persatuan waktu menjadi lebih besar pula, Penggunaan persentase perekat yang lebih tinggi memperoleh kerapatan serta keteguhan tekan yang tinggi juga dan memperlambat proses pembakaran pada briket, serta besarnya persentase perekat sangat mempengaruhi laju pembakaran pada briket.

Kadar abu yang terkandung dalam A3B2 sangat tinggi dan ini yang menyebabkan tingginya nilai laju pembakaran yang terjadi. Suhu akan berbanding lurus dengan massa, kenaikan suhu 
dapat menyebabkan massa sampel briket akan lebih cepat habis dan berdampak pada lebih pendeknya waktu pembakaran sehingga laju pembakaran akan semakin besar, dan dapat juga disebabkan oleh densitas briket, semakin besar densitas briket maka pori-pori briket akan lebih padat sehingga uap air dan laju pembakaran sulit untuk berdifusi yang berdampak pada lamanya waktu pembakaran briket.

\section{KESIMPULAN DAN SARAN}

\section{Kesimpulan}

Berdasarkan hasil penelitian dapat disimpulkan bahwa arang bambu tabah dan arang sekam padi dapat digunakan menjadi bahan baku pembuatan briket, dimana interaksi antar perlakuan jenis bahan baku dan persentase perekat memberikan pengaruh yang signifikan terhadap parameter mutu briket yang dihasilkan. Selanjutnya perlakuan A2B2 (arang sekam padi 85gram perekat 15 gram) merupakan perlakuan yang menghasilkan kualitas briket paling baik dibandingkan perlakuan lainnya, dimana kadar air yang dihasilkan sebesar 3,49\% bb, kadar abu 34,85\%, kadar zat menguap 31,30\% dan laju pembakarannya selama 75,60 gr/menit.

\section{Saran}

Saran yang diberikan adalah perlu dilakuakn kajian tentang jenis bahan baku lain dari limbah biomassa selain sekam dan bambu dengan persentase perekat yang berbeda. Selanjutnya perlu dilakukan adanya pengujian tambahan terhadap parameter mutu lainnya seperti kerapatan, keteguhan tekan, kadar karbon terikat dan nilair kalor agar briket arang bisa lebih layak digunakan.

\section{DAFTAR PUSTAKA}

Batubara, B., \& Jamilatun, S. (2012). Sifat-Sifat Penyalaan dan Pembakaran Briket Biomassa, Briket Batubara dan Arang Kayu. Jurnal Rekayasa Proses, 2(2), 37-40. https://doi.org/10.22146/jrekpros.554

Faiz, T. A., Harahap, L. A., \& Daulay, S. B. (2015). Pemanfaatan Tongkol Jagung dan Limbah Teh Sebagai Bahan Briket. Jurnal Rekayasa Pangan Dan Pertanian, 4(3), 427-432.

Handayani, R. T., \& Suryaningsih, S. (2019). Pengaruh Suhu Karbonisasi dan Variasi Kecepatan. 4(2), 98-103.

Hastiawan, I., Ernawati, E., Noviyanti, A. R., Eddy, D. R., \& Yuliyati, Y. B. (2018). Pembuatan briket dari limbah bambu dengan memakai. Dharmakarya: Jurnal Aplikasi Ipteks Untuk
Masyarakat, 7(3), 154-156.

Hendra, D. (2007). Pembuatan Briket Arang Dari Campuran Kayu, Bambu, Sabut Kelapa Dan Tempurung Kelapa Sebagai Sumber Energi Alternatif. In Jurnal Penelitian Hasil Hutan (Vol. 25, Issue 3, pp. 242-255). https://doi.org/10.20886/jphh.2007.25.3.242255

Isa, I. (2012). Briket Arang Dan Arang Aktif Dari Limbah Tongkol Jagung. Universitas Negeri Gorontalo, $1-50$. http://repository.ung.ac.id/get/simlit/1/168/2/ Briket-Arang-Dan-Arang-Aktif-DariLimbah-Tongkol-Jagung.pdf

Iskandar, T., \& Rofiatin, U. (2017). Karakteristik Biochar Berdasarkan Jenis Biomassa Dan Parameter Proses Pyrolisis. Jurnal Teknik Kimia, 12(1), 28-34. https://doi.org/10.33005/tekkim.v12i1.843

Ismayana, A., \& Afriyanto, M. R. (2011). Pengaruh Jenis Dan Kadar Bahan Perekat Pada Pembuatan Briket Blotong Sebagai Bahan Bakar Alternatif. J. Tek. Ind. Pert, 21(3), 186193.

Kencana, P. K. D., Widia, W., \& Antara, N. S. (2012). Praktek baik budi daya bambu rebung tabah (Gigantochloa nigrociliata BUSEKURZ). $1-69$. https://bamboeindonesia.files.wordpress.com/ 2012/06/budidaya-bambu-rebung-tabah.pdf

Muhammad, D. R. A., Parnanto, N. H. R., \& Widadie, F. (2018). Kajian Peningkatan Mutu Briket Arang Tempurung Kelapa Dengan Alat Pengering Tipe Rak Berbahan Bakar Biomassa. Jurnal Teknologi Hasil Pertanian, 6(1). https://doi.org/10.20961/jthp.v0i0.13500

Musabbikhah, Saptoadi, H., Subarmono, \& Arif Wibisono, M. (2015). optimasi proses pembuatan briket biomassa menggunakan metode yang ramah lingkungan (Optimization of Biomass Briquettes Production Process Using Taguchi Method to Fulfill The Need of Environment Friendly Alternative Fuel) Diterima : 15 Desember 2014. J. Manusia Dan Lingkungan, 22(1), 121-128.

Ningsih, E., Mirzayanti, Y. W., Himawan, H. S., \& Indriani, H. M. (2016). Pengaruh Jenis Perekat pada Briket dari Kulit Buah Bintaro terhadap Waktu Bakar. Prosiding Seminar Nasional Teknik Kimia "Kejuangan" Pengembangan Teknologi Kimia Untuk Pengolahan Sumber Daya Alam Indonesia, 1-8.

Purwanto, D. (2014). Pengaruh Tekanan Kempa Dan Persentase Perekat Terhadap Sifat Biobriket Dari Limbah Tempurung Sawit. Jurnal Riset Industri Hasil Hutan, 7(2), 1. https://doi.org/10.24111/jrihh.v7i2.1225 
Putra, H. P., \& Indonesia, U. I. (2018). Study Karakteristik Briket Berbahan Dasar Limbah Bambu dengan Menggunakan Perekat Nasi. December 2013.

Sa'diyah, H., Nurhimawan, S., Fatoni, S. A., Irmansyah, I., \& Irzaman, I. (2016). Ektraksi Silikon Dioksida Dari Daun Bambu. V, SNF2016-BMP-13-SNF2016-BMP-16. https://doi.org/10.21009/0305020303

Silviana, \& Purbasari, A. (2009). Kajian Awal Pemanfaatan Kulit Biji Nyamplung Sebagai Briket Bioarang. Kajian Awal Pemanfaatan Kulit Biji Nyamplung Sebagai Briket Bioarang, 6.

Siwi, H., Sirun, A., \& Arungpadang, T. A. R. (2017). Briket Campuran Arang Tempurung Kelapa dan Enceng Gondok Hasil Pirolisis. 1, $61-68$.

Sudarja. (2009). Analisis Rekayasa dan Karakterisasi Briket Bahan Bakar dari Limbah Serat Kenaf. Jurnal Ilmiah Semesta Teknika, 12(1), 92-98.

Sudding, \& Jamaluddin. (2015). Pengaruh Jumlah Perekat Kanji terhadap Lama Briket Terbakar menjadi Abu. Jurnal Chemical, 16(1), 27-36.

Vachlepi, A., \& Suwardin, D. (2013). Penggunaan Biobriket Sebagai Bahan Bakar Alternatif Dalam Pengeringan Karet Alam. Warta Perkaretan, 32(2), 65 . https://doi.org/10.22302/ppk.wp.v32i2.38

Wibowo, A. S. (2009). Kajian pengaruh komposisi dan perekat pada pembuatan briket sekam padi terhadap kalor yang dihasilkan. Universitas Stuttgart.

Yorganc1, B. (2018). Title. Gastrointestinal Endoscopy, 10(1), 279-288. http://dx.doi.org/10.1053/j.gastro.2014.05.02 3\%0Ahttps://doi.org/10.1016/j.gie.2018.04.0 13\%0Ahttp://www.ncbi.nlm.nih.gov/pubmed /29451164\%0Ahttp://www.pubmedcentral.ni h.gov/articlerender.fcgi?artid=PMC5838726 \%250Ahttp://dx.doi.org/10.1016/j.gie.2013.0 7.022 